\title{
Saccharomyces cerevisiae-based probiotic as novel anti-fungal and anti-inflammatory agent for therapy of vaginal candidiasis
}

\author{
E. Gabrielli ${ }^{1 \#}$, E. Pericolini ${ }^{1,2 \#}$, N. Ballet ${ }^{3}$, E. Roselletti ${ }^{1}$, S. Sabbatini ${ }^{1}$, P. Mosci ${ }^{4}$, A. Cayzeele Decherf ${ }^{5}$, F. Pélerin ${ }^{5}$, \\ S. Perito ${ }^{1}$, P. Jüsten ${ }^{5}$ and A. Vecchiarelli ${ }^{1^{*}}$ \\ ${ }^{1}$ Department of Medicine, University of Perugia, Sant'Andrea delle Fratte, 06132 Perugia, Italy; ${ }^{2}$ Department of Diagnostic, \\ Clinic and Public Health Medicine, University of Modena and Reggio Emilia, 41125 Modena, Italy, ${ }^{3}$ Lesaffre International, \\ Lesaffre Group, 147 rue Gabriel Péri, 59700 Marcq-en-Baroeul, France; ${ }^{4}$ Department of Veterinary Medicine, University \\ of Perugia, 06126 Perugia, Italy; ${ }^{5}$ Lesaffre Human Care, Lesaffre Group, 137 rue Gabriel Péri, 59700 Marcq-en-Baroeul, \\ France; anna.vecchiarelli@unipg.it; \#these authors contributed equally to this work
}

Received: 16 August 2017 / Accepted: 26 October 2017

(c) 2018 Wageningen Academic Publishers

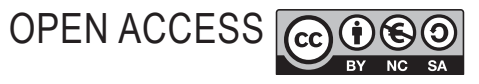

RESEARCH ARTICLE

\begin{abstract}
Previously we demonstrated that the treatment with live Saccharomyces cerevisiae exerts beneficial therapeutic effects against vaginal candidiasis. Here, we address potential mechanisms particularly examining the probiotic capacity to modulate both fungus and host-related factors. We show that the S. cerevisiae-based probiotic markedly affects the expression of virulence traits of Candida albicans such as aspartyl proteinases (SAPs) as well as hyphae-associated proteins Hwp1 and Ece1 in the vaginal cavity. On the host side, the probiotic suppression of the influx of neutrophils caused by the fungus into the vaginas of the mice is likely related to: (1) lower production of interleukin-8; and (2) inhibition of SAPs expression. However, these neutrophils displayed reactive oxygen species hyperproduction and increased killing activity as compared to the neutrophils of placebo-treated mice. There was no evidence of any cytotoxic effect by the probiotic, either when used in vivo on vaginal epithelial cell and organ architecture, or in in vitro in human vaginal epithelium. Inactivated yeast cells did not affect any of the factors above. In summary, the data suggest that the beneficial effect exerted by this S. cerevisiae-based probiotic is the result of its interference with the expression of fungus virulence factors coupled with the modulation of the inflammatory response of the host.
\end{abstract}

Keywords: yeasts, vaginal inflammation, beneficial microbes, vaginal candidiasis

\section{Introduction}

Probiotics are living microbial preparations able to provide health benefits to the host by affecting microbiota balance, composition and activity. It has been shown that probiotics can change the microbiota composition by increasing the populations of beneficial and protective bacteria, e.g. bifidobacteria and lactic acid bacteria, while reducing or arresting the pathogenic ones in both animal models and human studies (Looijer-Van Langen and Dieleman, 2009; Mennigen and Bruewer, 2009).

In turn, the above activities can influence the regulation of the host immune response which has become an important, potential target of probiotics. Improvements of the immune function in probiotic-treated hosts appear to be related not only to the burden of the beneficial bacterial population but also to the capacity of some of the metabolites secreted by these bacteria to modify the expression of basic functions of immune cells, such as cytokine production. This is clearly observed in the intestinal epithelium. In particular, the inhibition of pro-inflammatory cytokine expression in mesenteric lymph nodes, such as interferon- $\gamma$ and interleukin (IL)-2, was observed (Cavaglieri et al., 2003). Differential effects of short-chain fatty acids on proliferation and production of pro- and anti-inflammatory cytokines by cultured lymphocytes (Cavaglieri et al., 2003) could be a consequence of direct interaction of some bacterial cell surface components such as lipoteichoic acids and lipopolysaccharides with pattern recognition receptors 
of host cells. These multiple interactions can lead to a complex cascade of cellular events fostering the regulation of immune response (Medzhitov, 2007; Vance et al., 2009).

Among yeasts, Saccharomyces cerevisiae var. boulardii has been considered to be a proven probiotic since 1950; it is commercially available throughout the world, with a major indication as an antidiarrhetic agent. This probiotic is able to antagonise the inflammatory mediators that lead to intestinal tissue destruction, which may be achieved via secretion of anti-inflammatory factors (Sougioultzis et al., 2006), the inhibition of tumour necrosis factor- $\alpha$ transcription (Dalmasso et al., 2006), and the upregulation of IL-10 induction (Pontier-Bres et al., 2014). Other mechanisms of immunomodulation achievable by the use of the above yeast have been described (Badia et al., 2012; Martins et al., 2009, 2013).

S. boulardii and S. cerevisiae species are genetically very close, however, there are differences, which could be related to the number of genes involved in protein synthesis and stress response (Cascio et al., 2013; Edwards-Ingram et al., 2007). Relative to $S$. boulardii, few studies exist about the probiotic properties of $S$. cerevisiae. In particular, studies focused on the effect of S. cerevisiae administration on gastrointestinal disorders (Sivignon et al., 2015) and on the increase of survival and therapeutic potential of probiotic Lactobacillus rhamnosus (Lim et al., 2015). S. cerevisiae CNCM I-3856 is already recognised for these probiotic properties (Cayzeele-Decherf et al., 2017; Pineton de Chambrun et al., 2015; Spiller et al., 2016).

We previously demonstrated that local administration of $S$. cerevisiae live yeast (encoded GI) accelerates the clearance of Candida albicans from the vagina of experimentallyinfected mice (Pericolini et al., 2017). We showed that the enhanced fungal clearance was related to numerous effects directly exerted on Candida by the probiotic in an in vitro experimental system including mechanical ones, e.g. coaggregation and inhibition of hypha formation (Pericolini et al., 2017). In this study, we have expanded on the effects of this S. cerevisiae-based probiotic (GI) on the expression of pathogenicity determinants by C. albicans in vivo during vaginal candidiasis; in addition, we also examined whether the administration of S. cerevisiae could dampen local inflammation by affecting the number and functions of a landmark sign of inflammation, such as neutrophil (PMN) influx.

\section{Materials and methods}

\section{Study products}

The products studied were provided by Lesaffre Human Care (Marcq-en-Baroeul, France). GI is a proprietary, well-characterised strain of Lesaffre, registered in the
French National Collection of Cultures of Microorganisms (CNCM) under the number I-3856. The S. cerevisiae species was determined by using phenotypic (API ID32C, Biomerieux SAS, Marcy l'Etoile, France) and genotypic reference methods (genetic amplification and sequencing of 26S DNA) (Kurtzman and Robnett, 1997, 1998). Moreover, strain CNCM I-3856 has been characterised by PCR Interdelta typing techniques (CEN, 2009) and other genetic methods (e.g. complete genome sequencing).

The specification of the probiotic product is $\geq 5 \times 10^{9} \mathrm{cfu} / \mathrm{g}$ and the concentration of the batch used for these trials was $1 \times 10^{10} \mathrm{cfu} / \mathrm{g}$. Inactivated yeast obtained by drum-drying of live yeast S. cerevisiae CNCM I-3856 was used as the control strain.

\section{Microbial strains and growth conditions}

The origin and the characteristics of the highly virulent C. albicans strain (CA-6) have previously been described (Bistoni et al., 1986). The cultures were maintained by serial passages on YPD agar (yeast extract, peptone and dextrose anhydrous. All from Sigma-Aldrich, St. Louis, MO, USA). The yeast cells were harvested by suspending a single colony in saline, washed twice, counted in a haemocytometer and adjusted to the desired concentration. Staphylococcus aureus was isolated from an Italian patient and obtained from the laboratory of Bacteriology of Santa Maria della Misericordia Hospital, Perugia, Italy. S. aureus was grown in mannitol salt agar (MSA; Oxoid, Basingstoke, UK).

\section{Ethics statement}

The procedures involving the animals and their care were conducted in conformity with national and international laws and policies. All animal experiments were performed in agreement with the EU Directive 2010/63, the European Convention for the Protection of Vertebrate Animals used for Experimental and other Scientific Purposes, and the National Law 116/92. The protocol was approved by Perugia University Ethics Committee for animal care and use (Comitato Universitario di Bioetica, permit number 149/2009-B). All the animals were housed in the animal facility of the University of Perugia (Authorisation number 34/2003A). Mice were acclimatised for a week before starting the experiments. 5-8 mice were housed in each cage and were provided with food and water ad libitum. All efforts were made to minimise suffering during experiments.

\section{Mice}

Female CD1 mice obtained from Charles River (Calco, Italy) were used at 4 to 6 weeks of age. Animals were used under specific-pathogen free conditions that included testing sentinels for unwanted infections; according to 
the Federation of European Laboratory Animal Science Association standards, no infections were detected.

\section{Infection and treatment}

Mice were maintained under pseudoestrus condition by subcutaneous injection at the base of a fold of loose skin (area at the neck) (Shimizu, 2004) of $0.2 \mathrm{mg}$ estradiol valerate in $100 \mu \mathrm{l}$ of sesame oil (Sigma-Aldrich) 5 days prior to infection and then weekly until the completion of the study. Mice anaesthetised with 2.5-3.5 (v/v) isoflurane gas were injected intravaginally with or without saline, GI (10 or $100 \mathrm{mg} / \mathrm{ml}, 10 \mu \mathrm{l} / \mathrm{mouse}$ ) or inactivated whole yeast used as control strain $(100 \mathrm{mg} / \mathrm{ml}, 10 \mu \mathrm{l} /$ mouse $)$ every day starting from day +1 post-infection with $10 \mu \mathrm{l}$ of $2 \times 10^{9}$ cells $/ \mathrm{ml}$ of C. albicans. In selected experiments, uninfected control mice were daily injected intravaginally with saline, GI or inactivated yeast (both $100 \mathrm{mg} / \mathrm{ml}, 10 \mu \mathrm{l} /$ mouse). Candida cell suspensions were administered with a mechanical pipette into the vaginal lumen, close to the cervix. To favour vaginal contact and adsorption of fungal cells, mice were held head down for $1 \mathrm{~min}$ following inoculation. Mice were then allowed to recover for 24-48 h, during which the $C$. albicans infection was established.

\section{Vaginal washes}

At day $+3,+8$ and +14 post-infection, vaginal washes were conducted using $250 \mu \mathrm{l}$ of saline, given in five separate 50 $\mu \mathrm{l}$ volumes, with repeated aspiration for 10 to 20 times. Vaginal washes were centrifuged and the supernatants were collected and tested for cytokine and beta-defensins production. The total cellular fraction was used for flow cytometry analysis, killing activity and gene expression analysis.

\section{Cell lines and vaginal epithelium}

The human A-431 vaginal epithelial cell line and the human HeLa epithelial cervical cell line, obtained from ATCC (Manassas, VA, USA), were grown in Dulbecco's Modified Eagle Medium (DMEM; EuroClone S.p.A., Pero, Italy) plus $10 \%$ of fetal calf serum (FCS). Human vaginal epithelium was obtained by the differentiation of A-431 cell line as previously described (Ridge et al., 1991).

\section{Flow cytometry analysis}

Total cellular fractions obtained from vaginal washes were fixed with $1.5 \%$ formalin for $10 \mathrm{~min}$, washed, allowed to react with a phycoerythrin-conjugated mAb to mouse Ly-6G (PMN; $10 \mu \mathrm{l} / 10^{6}$ cells; Rat IgG $2 \mathrm{~b}$; AbD Serotec, Kidlington, UK) for $20 \mathrm{~min}$ at room temperature (RT) in the dark. After incubation, cells were washed twice with fluorescent buffer (FB), resuspended in $0.5 \mathrm{ml}$ of $\mathrm{FB}$ and then analysed by flow cytometry using a FACSCalibur system (Becton
Dickinson, Franklin Lakes, NJ, USA). Data are expressed as the percentage of positive cells (PMN) (Pericolini et al., 2015). Autofluorescence was assessed by using untreated cells. Control staining of cells with irrelevant Abs was used to obtain background fluorescence values.

\section{Cytokine and beta-defensins production}

The supernatants from vaginal washes were collected and tested for IL- 8 and beta-defensins levels by specific ELISA assays (both from MyBioSource, San Diego, CA, USA). Cytokine and beta-defensins titres were calculated relative to standard curves.

\section{Peritoneal neutrophils}

After 14 days post vaginal infection, peritoneal neutrophils (pPMN) from uninfected mice, were collected $18 \mathrm{~h}$ after the intraperitoneal injection of $0.5 \mathrm{ml}$ endotoxin-free $10 \%$ thioglycolate solution (Difco, Becton Dickinson) and used as a control of killing activity.

\section{Antimicrobial activity}

$100 \mu \mathrm{l}$ of cellular fraction $\left(1 \times 10^{4}\right.$ cells $\left./ \mathrm{ml}\right)$, obtained from vaginal washes of mice treated for 14 days as described above, or pPMNs $\left(1 \times 10^{4}\right.$ cells $\left./ \mathrm{ml}\right)$ were incubated in flat bottom 96-well microtiter tissue culture plates with $100 \mu \mathrm{l}$ of S. aureus $\left(2 \times 10^{2}\right.$ cells $\left./ \mathrm{ml}\right)$ in RPMI- $1640+5 \%$ FCS for $2 \mathrm{~h}$ at $37{ }^{\circ} \mathrm{C}$ plus $5 \% \mathrm{CO}_{2}$. After incubation, plates were vigorously shaken and cells were lysed by adding Triton X-100 (0.1\% in distilled water; final concentration in the well $0.01 \%)$. Serial dilutions were prepared in distilled water from each well. The samples were then spread on MSA in triplicate and $\mathrm{cfu}$ values were evaluated after $24 \mathrm{~h}$ of incubation at $37^{\circ} \mathrm{C}$. Killing activity was expressed as the percentage of cfu inhibition (Mosci et al., 2014). In selected experiments, the total cellular fraction or pPMNs (both $4 \times 10^{6}$ cells $/ \mathrm{ml}$ ) were incubated with PE-conjugated $\mathrm{mAb}$ to mouse Ly-6G (PMN; $10 \mu \mathrm{l} / 10^{6}$ cells; Rat IgG $2 \mathrm{~b}$; AbD Serotec) for $20 \mathrm{~min}$ at RT in the dark. After incubation, cells were washed and incubated with $1 \mu \mathrm{M}$ of 2,7'-dichlorofluoresceindiacetate for $30 \mathrm{~min}$ at RT and then incubated in the presence of phorbol myristate acetate $(100 \mathrm{ng} / \mathrm{ml})$ (Sigma-Aldrich) for $1 \mathrm{~h}$ at $37{ }^{\circ} \mathrm{C}$ plus $5 \% \mathrm{CO}_{2}$. After incubation, cells were analysed by flow cytometry using a FACSCalibur system. Data are expressed as the mean of fluorescence intensity of 2,7'-dichlorofluorescein (DCFH) on gated PMN positive cells. Autofluorescence was assessed by using untreated cells. 


\section{Quantitative analysis of SAP2, SAP6, HWP1 and ECE1 genes expression}

Vaginal washes of mice, intravaginally infected and treated as described above with GI (10 or $100 \mathrm{mg} / \mathrm{ml}, 10 \mu \mathrm{l} / \mathrm{mouse}$ ) or inactivated yeast $(100 \mathrm{mg} / \mathrm{ml}, 10 \mu \mathrm{l} /$ mouse $)$, were obtained 3, 8 and 14 days post-infection with $10 \mu \mathrm{l}$ of $2 \times 10^{9}$ cells/ml of C. albicans. Vaginal washes were centrifuged at 3,000 rpm for $5 \mathrm{~min}$, then cellular fractions were lysed using Trizol reagent (Life Technology, Waltham, MA, USA).

Total RNA was extracted and retro-transcribed by using the Moloney murine leukaemia virus reverse transcriptase reaction (M-MLV RT), as described in the manufacturer's instructions. cDNA concentration was determined using a spectrophotometer. C. albicans ACT1, SAP2, SAP6, HWP1 and $E C E 1$ genes were detected using primers reported elsewhere (Moyes et al., 2016; Naglik et al., 2006, 2008). Real-time PCR (quantitative PCR) was performed in 96-well PCR plates using SYBR green (all from BioRad, Hercules, CA, USA). For real-time PCR reactions 100 ng of cDNA was used. All samples were measured in triplicate. The relative level of Candida genes expression at different time-points post-infection was reported as $2^{-\Delta \Delta C T}$ relative to transcripts of C. albicans inoculum (Pericolini et al., 2017). Amplification conditions used were the same for ACT1, SAP2, SAP6, HWP1 and ECE1: 3 min at $95^{\circ} \mathrm{C}, 40$ cycles of $10 \mathrm{~s}$ at $95^{\circ} \mathrm{C}$ and $30 \mathrm{~s}$ at primer specific annealing temperature. The experiments were performed using the Eppendorf Mastercycler (Hamburg, Germany).

\section{Cytotoxicity assay}

A-431 and HeLa cells (both $1 \times 10^{6} / \mathrm{ml}$ ) were grown for $24 \mathrm{~h}$ in 96 -well microtiter plates $(100 \mu \mathrm{l} /$ well $)$. Vaginal epithelium was obtained by differentiation of A-431 cell line $\left(1 \times 10^{6} / \mathrm{ml}\right)$ for 5 days in 96 -well microtiter plates $(100$ $\mu \mathrm{l} /$ well) (Ridge et al., 1991). Before stimulation, cells were incubated for $2 \mathrm{~h}$ in DMEM medium without FCS. Cells were then incubated in the presence or absence of $100 \mu \mathrm{l}$ of inactivated yeast (control strain) or GI (both $100 \mathrm{mg} / \mathrm{ml}$ ) for $1 \mathrm{~h}$ at $37^{\circ} \mathrm{C}$ plus $5 \% \mathrm{CO}_{2}$, extensively washed five times with phosphate buffered saline (PBS) and then incubated with $100 \mu \mathrm{l}$ of $\mathrm{C}$. albicans $\left(1 \times 10^{6} / \mathrm{ml}\right)$ for $18 \mathrm{~h}$ at $37^{\circ} \mathrm{C}$ plus $5 \% \mathrm{CO}_{2}$. After co-incubation, the epithelial cell damage was determined by the release of lactate dehydrogenase (LDH) into the surrounding medium. LDH was measured spectrophotometrically at $492 \mathrm{~nm}$ using a Cytotoxicity Detection kit (LDH) from Pierce (Thermo Scientific, Waltham, MA, USA). The percent cytotoxicity of epithelial cells infected with $C$. albicans was calculated as follows: ((LDH activity of treated cells - spontaneous LDH activity)/ (maximum LDH activity - spontaneous LDH activity) $\times$ 100 and compared to $100 \%$ C. albicans damage induced in each cell type (Wachtler et al., 2011).
In selected experiments, A-431, HeLa cells and vaginal epithelium, were incubated in the presence or absence of $100 \mu \mathrm{l}$ of different doses of inactivated yeast or GI (both 2, 10 or $100 \mathrm{mg} / \mathrm{ml}$ ) for $1 \mathrm{~h}$ at $37{ }^{\circ} \mathrm{C}$ plus $5 \% \mathrm{CO}_{2}$, then extensively washed five times with PBS. After washing, 100 $\mu \mathrm{l}$ of medium or $100 \mu \mathrm{l}$ of C. albicans $\left(1 \times 10^{6} / \mathrm{ml}\right)$, as positive control, were added. After $18 \mathrm{~h}$ of incubation at $37^{\circ} \mathrm{C}$ plus $5 \% \mathrm{CO}_{2}$, the epithelial cell damage was determined by the release of LDH into the surrounding medium as above described. The percentage cytotoxicity of epithelial cells treated with different doses of inactivated yeast, GI or with C. albicans, was expressed as \% of LDH release. The lysis buffer was used as positive control.

\section{Histology}

Mice, treated as above described, were sacrificed and vaginas were removed and immediately fixed in $10 \%$ (v/v) neutral buffered formalin for $24 \mathrm{~h}$. They were then dehydrated, embedded in paraffin, sectioned into 3- to 4- $\mu \mathrm{m}$ thick sections, and stained with haematoxylin/eosin.

\section{Statistical analysis}

The results reported are the means \pm standard error of the mean (SEM) of 6-9 different mice from 2-3 experiments. For LDH assay the results reported are the means \pm SEM of triplicate samples of four different experiments. Data were evaluated using ANOVA. Post-hoc comparisons were done with Bonferroni's test and with Dunnet's test for LDH assay. A value of $P<0.05$ was considered significant.

\section{Results}

As reported in detail in the Materials and Methods section, in our experimental model, mice were kept under pseudoestrus and infected with $C$. albicans. The probiotic was administered intravaginally daily while monitoring the infection; vaginal cells or cell-free vaginal washes were examined to determine the effects of GI compound on fungus and host determinants of vaginal candidiasis.

\section{Effects of Saccharomyces cerevisiae on Candida albicans virulence expression in the mouse vagina}

Among the virulence factors of C. albicans, the aspartyl proteases (SAPs) have been shown to play a role in both experimental and clinical vaginitis (Naglik et al., 2008; Pericolini et al., 2015). Specifically, in this study, we focused on Sap2 and Sap6 that are strictly associated to immunopathogenic process of vaginal candidiasis. In particular, investigations by our research group showed that Sap2 and Sap6 induce an inflammatory response by monocytes in vitro (Gabrielli et al., 2015; Pietrella et al., 2013) and vaginal inflammation in vivo (Gabrielli et al., 2016; Pericolini et al., 2015). We therefore assessed the 
expression of two representative $S A P$ genes ( $S A P 2$ and $S A P 6)$ in the infected mouse vagina at various times after challenge of animals, treated or not, with two doses of the probiotic. The results reported in Figure 1A show that both doses of GI were able to produce a marked suppression of SAP2 expression both at its maximal expression (day 3 ) and during its declining expression (day 8). On day 14 post-challenge, low levels of SAP2 gene expression were detected, with minimal or negligible effects of the probiotic. A similar trend of GI inhibitory effect was also noticed on SAP6 gene expression, although this gene maintained an appreciable level of expression on day 14 (Figure 1B). No inhibition of SAP expression was observed with inactivated yeast used as control strain at the same concentration as the probiotic $(100 \mathrm{mg} / \mathrm{ml}, 10 \mu \mathrm{l} / \mathrm{mouse})$ (data not shown).

To gain further insight into the mechanism of the probiotic mediated inhibition of C. albicans hyphal growth observed in vitro (Pericolini et al., 2017), we analysed the expression of two important hyphal growth-associated genes, e.g. HWP1 (hyphal wall protein 1) and ECE1 (extent of cell elongation 1), in fungal cells recovered from vaginal washes at various time after challenge. In particular, Ece1 protein is essential for hypha initiation and elongation (Finkel and Mitchell, 2011; Sudbery, 2011). The HWP1 gene of C. albicans, encoding for a fungal cell wall protein required for hyphal development (Hofs et al., 2016; Naglik et al., 2011), was also tested in cells from vaginal washes. The results (Figure 2) show that both genes are appreciably expressed early (day 3) during C. albicans infection, and only negligibly later on. Importantly, the treatment with both doses of GI completely inhibited their expression. Conversely, inactivated yeast did not produce any inhibition of HWP1 and ECE1 gene expression at any time investigated (data not shown). Moreover, we have already showed that the daily intravaginal administration of GI significantly reduced $C$. albicans burden until 12 days post-infection (Pericolini et al., 2017).

Based on mechanical effects exerted on Candida by compounds, as shown by Pericolini et al. (2017), and considering that hyphal cells of $C$. albicans can directly damage host epithelial cells, and that some of the peptides derived from Ece1 processing have Candida-toxic activity
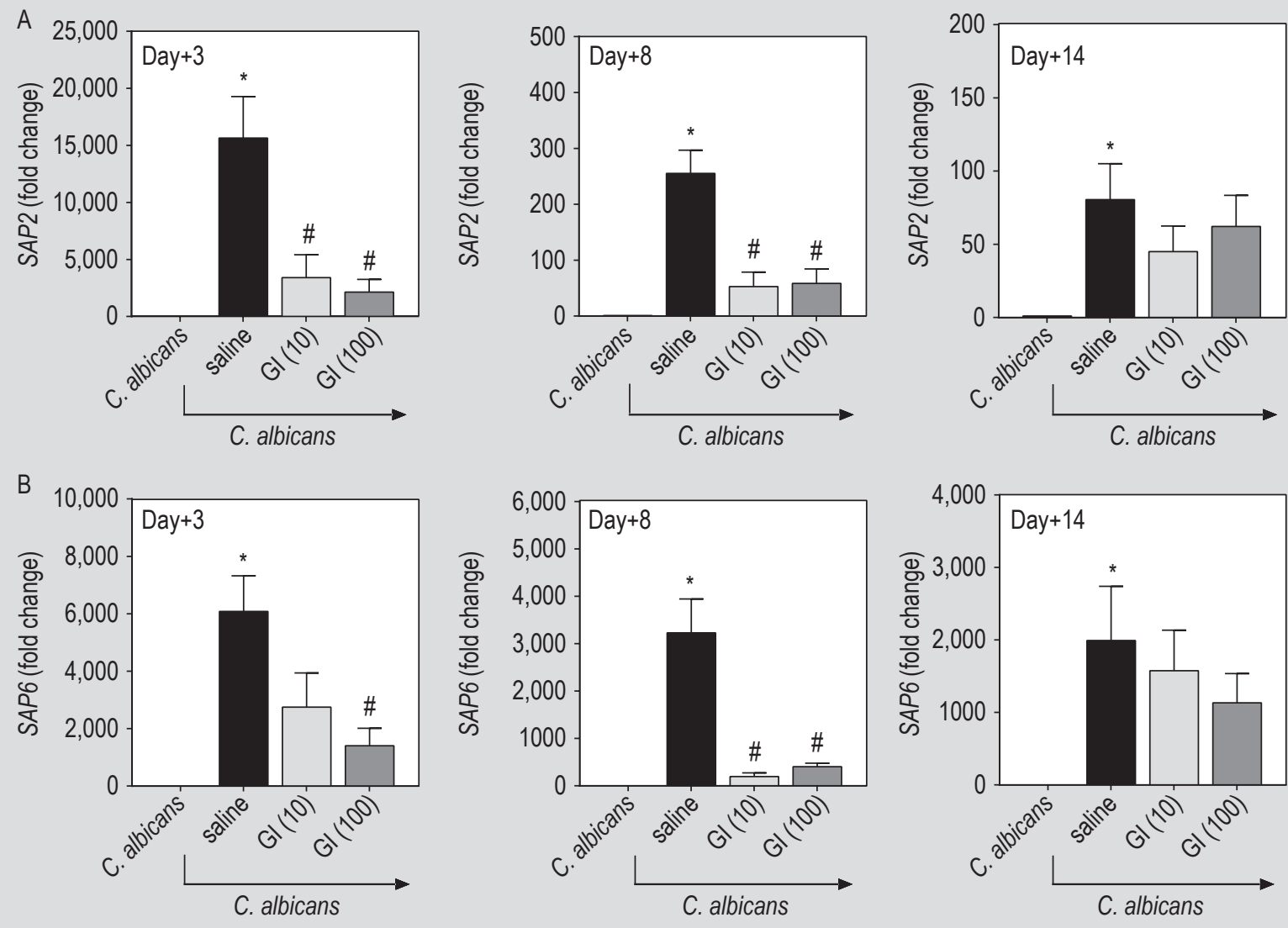

Figure 1. Effect of Saccharomyces cerevisiae live yeast (GI) on Candida albicans (A) SAP2 and (B) SAP6 expression during vulvovaginal candidiasis. cDNA quantities were reported as $2^{-\Delta \Delta C T}$ relative to transcripts expressed in the $C$. albicans inoculum (leftmost column in all graphs). Data show mean \pm standard error of the mean of triplicates samples of 6-8 different mice. ${ }^{*} P<0.05$ saline-treated infected mice vs fungal challenge. \# $P<0.05 \mathrm{Gl}$-treated infected mice vs saline-treated infected mice. 

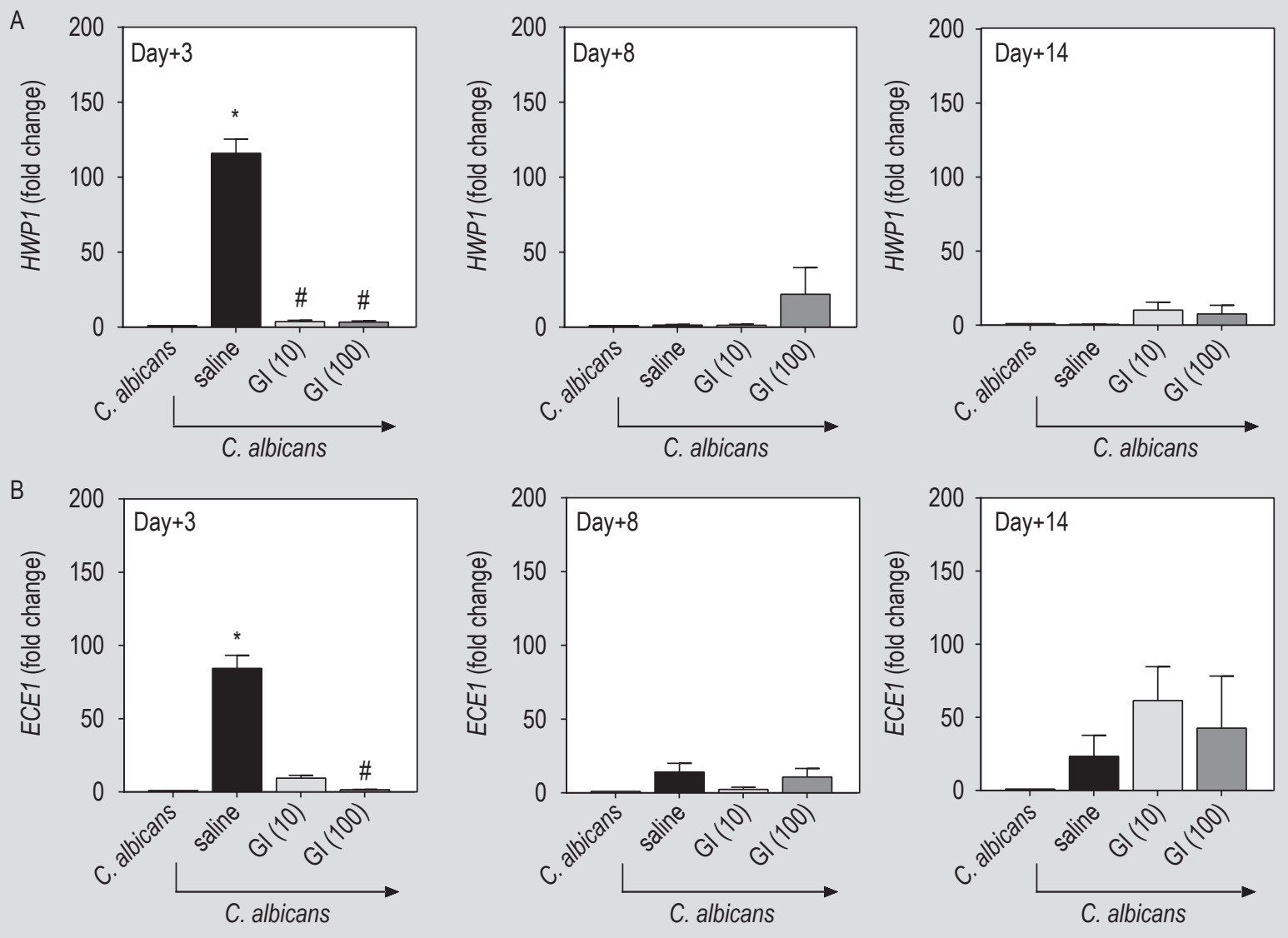

Figure 2. Effect of Saccharomyces cerevisiae live yeast (GI) on (A) HWP1 and (B) ECE1 expression during vulvovaginal candidiasis. cDNA quantities were reported as $2^{-\Delta \Delta C T}$ relative to transcripts expressed in the $C$. albicans inoculum (leftmost column of all graphs). Data show mean \pm standard error of the mean of triplicates samples of 6-7 different mice. ${ }^{*} P<0.05$ saline-treated infected mice vs fungal challenge. \# $P<0.05 \mathrm{Gl}$-treated infected mice vs saline-treated infected mice.

(Moyes et al., 2016), we also tested the possibility that GI exerts a protective role on vaginal and cervico-vaginal epithelial cells exposed to the fungus in vitro. This was done by analysing $\mathrm{LDH}$ release using the human vaginal epithelial cell line A-431, the human epithelial cervical cell line HeLa and human vaginal epithelium. The higher dose of GI produced a clearly protective effect on C. albicans-induced damage in all cell lines tested (Figure 3A). Importantly, the same dose of GI did not exert, by itself, any damage to all above-mentioned cells (Figure 3B).

\section{Effects of Saccharomyces cerevisiae on vaginal inflammation by Candida albicans}

\section{Neutrofil influx and activity}

PMN cells recruited to the vagina during $C$. albicans infection are considered a marker of inflammatory response and are heavily involved in the phlogistic process induced in mice by vaginal challenge with C. albicans. This process, uncoupled from the fungus infectious burden, is longlasting and can be related to the inflammation-promoting activity of some fungal products (Pericolini et al., 2015). As previously reported, the influx of PMN was massive in an early phase of vaginal infection with Candida and maintained a high level until day 30 post infection (Pietrella et al., 2011). Therefore, it was important to assess whether the probiotic was also capable of modulating PMN influx during the infection. To this aim, we first analysed the influx of PMNs into the mouse vagina 14 days post challenge and the effect of GI administration on it. As shown in Figure 4, the percentage of PMNs recruited to the mouse vagina is substantially reduced on treatment with high dose of GI (Figure 4A). In a second series of experiments, we asked whether some functional activities of PMN cells were affected by GI compound. Thus, we determined reactive oxygen species (ROS) production by vaginal PMNs and $\beta$-defensins presence in the vaginal washes. Figure 4B shows that PMNs from infected mice treated with both doses of GI produced more ROS than PMNs from salinetreated infected mice. In contrast, no effect on $\beta$-defensins production was shown by treatment with GI (Figure 4C). Furthermore, we analysed whether the increase of ROS production could influence antimicrobial capacity of cells 

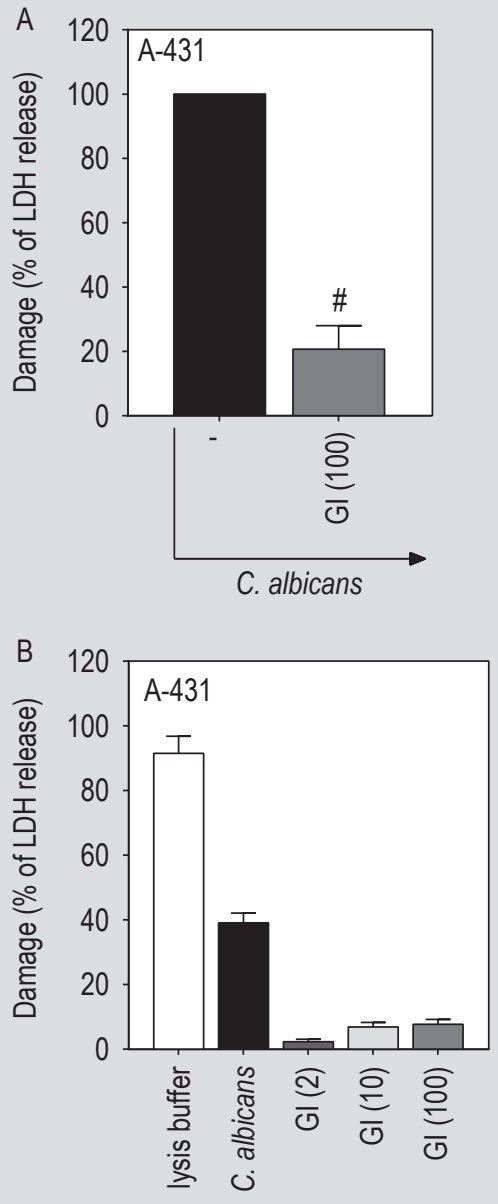
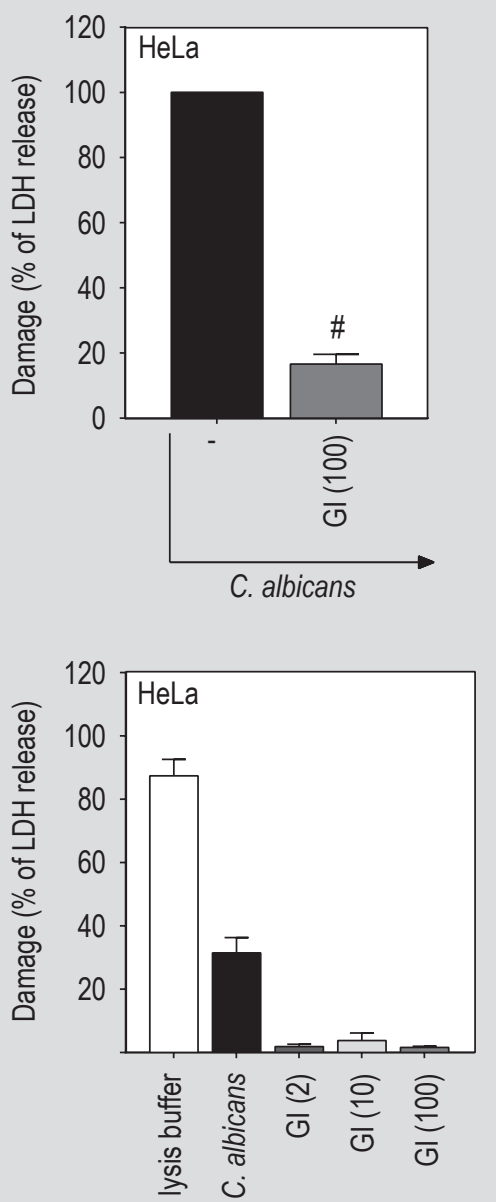
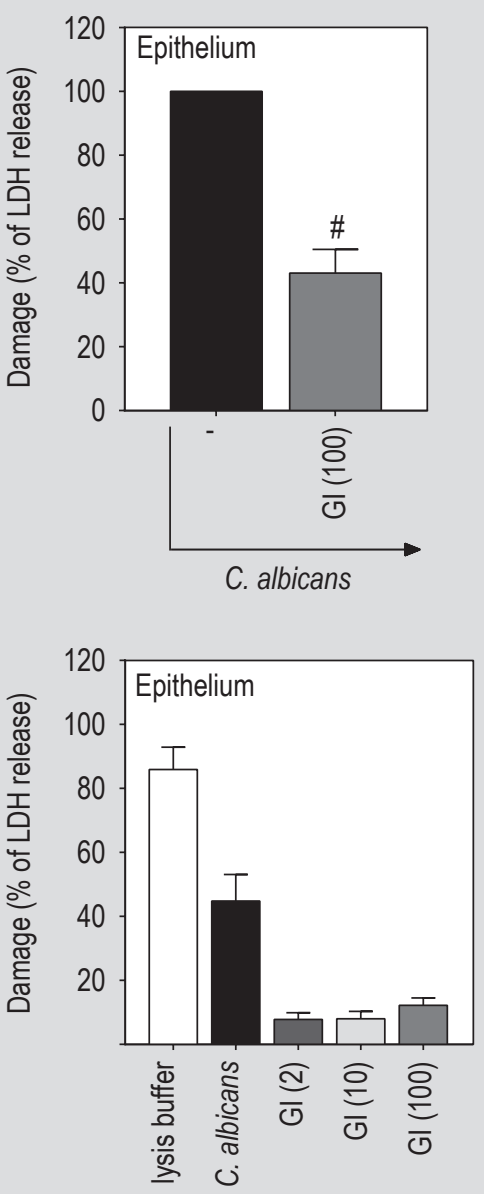

Figure 3. Effect of Saccharomyces cerevisiae live yeast (GI) on cellular damage in A-431 cells, HeLa cells, or vaginal epithelium. Cellular damage was expressed as percentage of lactate dehydrogenase release (LDH) (A and B) and compared to $100 \%$ Candida damage induced in each cell type (A). Data show the mean \pm standard error of the mean of triplicate samples of 4 different experiments. \# $P<0.05 \mathrm{Gl}$-treated vs untreated.

from vaginal washes (70\% PMN). Given that C. albicans is present in vagina of infected mice we tested the PMN activity against an unrelated microorganism, such as $S$. aureus. A significant enhancement of killing activity against S. aureus in the cellular fraction from GI-treated infected mice was observed (Figure 4D). The inactivated whole yeast used as control at dose of $100 \mathrm{mg} / \mathrm{ml}(10 \mu \mathrm{l} /$ mouse $)$ did not influence PMN infiltration nor ROS and nor $\beta$-defensins release and killing activity (data not shown).

IL-8 is a key cytokine associated with inflammatory responses and plays a major role in PMN recruitment and degranulation. Given that recruitment of PMNs into the vaginal environment is an essential factor for inflammation, IL-8 was tested in vaginal washes of mice treated with GI compound. The results show that $100 \mathrm{mg} / \mathrm{ml} \mathrm{GI}$ strongly reduced IL-8 production at each time point tested after Candida challenge, whereas a lower dose of GI only resulted in a reduction after 14 days (Figure 5). Inactivated whole yeast did not modulate IL-8 production (data not shown).
Altogether, these data show that PMNs, i.e. a landmark sign of vaginal inflammation, are not only reduced numerically, possibly due to decreased IL-8 secretion, but also positively stimulated for anti-microbial activity by the probiotic treatment.

\section{Histology}

Infiltration of PMNs in histological preparations from C. albicans infected mice, untreated or treated with a low dose of GI, was manifested 14 days after challenge (Figure $6 \mathrm{~A}, \mathrm{~B})$. This infiltration disappeared with the high dose of GI (Figure 6C). Histological examination of vaginal tissue of uninfected animals treated with saline (Figure 6D), or GI (Figure 6E) showed complete integrity of vaginal tissue, as well as no PMN recruitment confirming the absence of cytotoxicity for both compounds. 

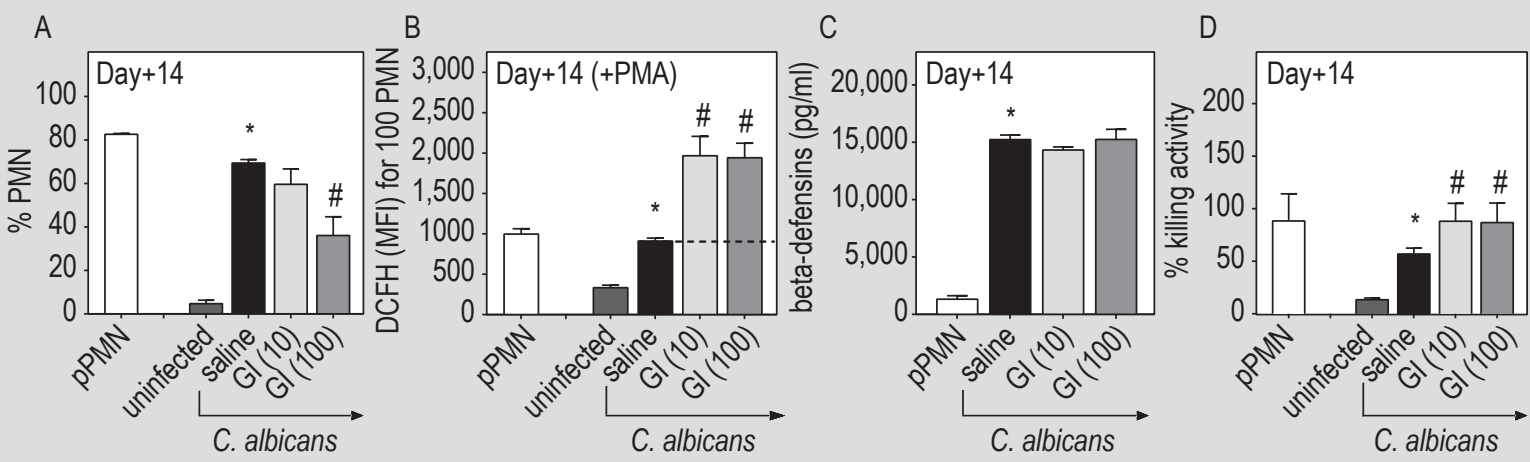

Figure 4. Effect of Saccharomyces cerevisiae live yeast (GI) on Candida albicans-induced neutrophil (PMN) vaginal influx. (A) Percentage of PMN in cellular fractions from vaginal washes. (B) Reactive oxygen species production as DCFH (mean of fluorescence intensity (MFI)).. (C) Total beta-defensins production. (D) Killing activity of vaginal cellular fractions or pPMNs against Staphylococcus aureus. * $P<0.05$ saline-treated infected mice vs saline-treated uninfected mice. \# $P<0.05$ Gl-treated infected mice vs saline-treated infected mice.
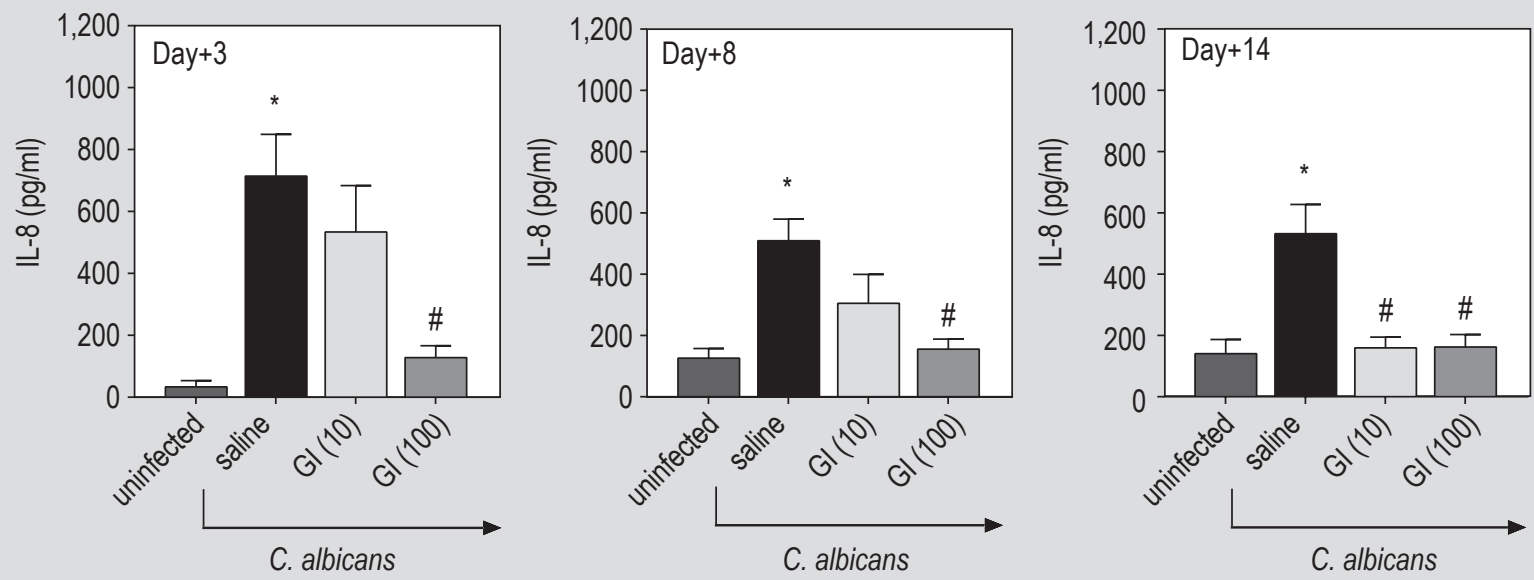

Figure 5. Effect of Saccharomyces cerevisiae live yeast (GI) on Candida albicans-induced interleukin 8 (IL-8) production. ${ }^{*} P<0.05$ saline-treated infected mice vs saline-treated uninfected mice. \# $P<0.05 \mathrm{Gl}$-treated infected mice vs saline-treated infected mice.

\section{Discussion}

In recent years, there has been an increasing interest on the modulation of intestinal microbiota and host immune responses by probiotics. Probiotics are live microorganisms that when administered in appropriate amounts provide an health benefit to the host (FAO/WHO, 2002). Various microorganisms have been considered as probiotic including bacteria, such as Lactobacillus, Bifidobacterium, Enterococcus species, and yeasts, such as S. cerevisiae (Cheung et al., 2009; Jubran et al., 2013; Nicholson et al., 2012; Tremaroli and Backhed, 2012). These microorganisms have been used extensively for both prevention and treatment of various inflammatory and intestinal disorders of infectious and non-infectious nature, such as inflammatory bowel disease (Sartor, 2005) and infectious diarrhoea (Van Niel et al., 2002). Several findings further support the hypothesis that probiotics could provide an approach for the management of stress response that contributes to intestinal dysfunction (Kennedy et al., 2014).

Expanding on our previous in vitro studies, we show here that daily intravaginal administration of S. cerevisiae CNCM I-3856 leads to a remarkable inhibition of the expression of several fungal components that play critical roles in fungal virulence at the vaginal level. Some of these components, such as secretory aspartyl proteinases, contribute to vaginal inflammation that is typical of candidal vaginitis. In addition, we show that recruited PMNs - a landmark inflammatory sign - are reduced in number, but not in their potential antimicrobial activity following treatment with the S. cerevisiae-based probiotic. Altogether, these effects can underlie the observed beneficial activity of GI on the clearance of the vaginal infection. Finally, we observed that the vagina and the vaginal tissue were totally preserved in architectural integrity in mice treated with GI. Treatment with the probiotic alone at doses used in our experimental 


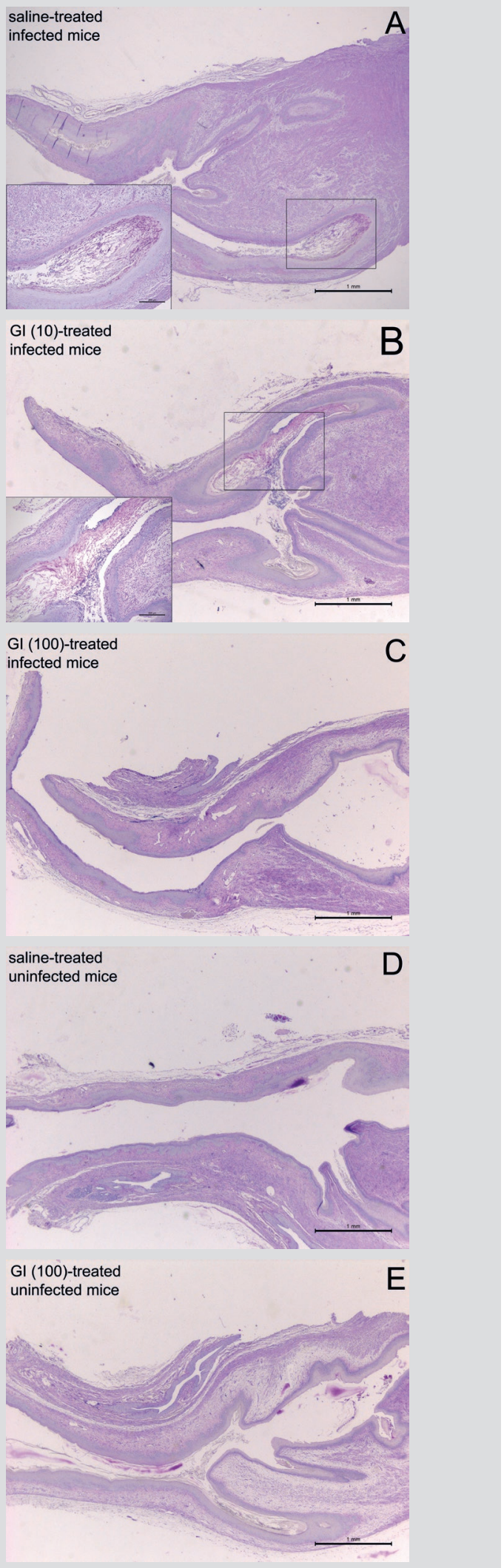

Figure 6. Histological analysis of vaginal tissues from infected mice (14 days post-infection) treated daily with saline (A), Saccharomyces cerevisiae live yeast (Gl) (10 or $100 \mathrm{mg} / \mathrm{ml}, 10 \mu \mathrm{l} /$ mouse) ( $B$ and $C$, respectively). Uninfected mice treated daily with saline (D) or GI (100 mg/ml, $10 \mu \mathrm{l} / \mathrm{mouse}$ ) (E) served as controls. system did not show any toxicity, here evaluated as damage to a vaginal epithelial cell line, a cervical cell line, and a human vaginal epithelium. More importantly, when these cells were infected with C. albicans, protection from fungusinduced damage was conferred by $S$. cerevisiae.

Previously we demonstrated that Saps can mediate inflammasome activation both directly, and via their secretion from C. albicans cells during vaginal infection (Pericolini et al., 2015). This activation participates greatly in inflammatory processes that characterise this pathology (Pericolini et al., 2015). Given that Sap2 also exerts a chemotactic activity (Gabrielli et al., 2016), the reduction by the probiotic of $C$. albicans-induced PMN influx into vagina could be ascribed, at least in part, to the marked inhibition of SAP2 expression, to which the noted inhibition of the SAP6 expression could also participate.

Furthermore, during vaginal candidiasis there is a consistent infiltration of PMNs, which represent about $70 \%$ of the inflammatory cellular exudates of the infected vagina (Figure 4A); therefore, the significant decrease of PMNs could be also accounted for the observed decrease in IL-8 in the vaginal washes of GI-treated infected animals. Of importance, this is the first observation that the treatment with this S. cerevisiae-based probiotic not only does not alter the microbicidal potential of PMNs, but actually appears to be able to enhance this potential since ROS and killing activity are increased, and $\beta$-defensins are not decreased by the probiotic. This suggests that PMNs could be active candidacidal cells in the presence of GI while they are not without treatment (Naglik et al., 2014; Williams, 2010).

Several anti-inflammatory effects have been reported for probiotics such as $S$. boulardii. Results from in vitro and in vivo experiments show that $S$. boulardii modulates the host's gastrointestinal immune system including IgA secretion as well as IL-10 production (Martins et al., 2009). In addition, anti-inflammatory ability was observed in a mouse model of Salmonella infection (Martins et al., 2013). Although several reports deal with S. boulardii, very few reports have studied effectiveness of $S$. cerevisiae in preventive or therapeutic treatment in infectious diseases. In a recent paper, we demonstrated that the treatment with live $S$. cerevisiae was therapeutic in vaginal candidiasis by accelerating the clearance of the fungus. This effect was due to multiple interactions of S. cerevisiae with C. albicans including promotion of coaggregation, inhibition of adherence to epithelial cells, and inhibition of Candida virulence factors (Pericolini et al., 2017). All these latter effects were only demonstrated in in vitro systems. In this report, we demonstrate that this S. cerevisiae-based probiotic markedly reduces the inflammatory response that is a key player in vaginal candidiasis (Peters et al., 2014; Vecchiarelli et al., 2015). In addition, several virulence factors of the fungus, including the recently described 
Ece1, a source of Candida toxic active peptides (Moyes et al., 2016), are indeed inhibited in vivo during vaginal candidiasis. Indeed, the acceleration of $C$. albicans clearance and attenuation of inflammatory response following treatment with S. cerevisiae probiotic is likely due to direct inhibition of aspartyl proteases production and yeast-hypha transition, two factors considered of utmost importance in the pathogenesis of vaginal candidiasis (Cassone et al., 2016). These effects, in addition to those shown in vitro, and coupled with the absence of obvious cytotoxicity of the product, demonstrate that the probiotic activity of $S$. cerevisiae studied here is of high complexity, with multiple and possibly interacting factors. We suggest that at least some of the above in vitro and in vivo effects of GI can provide a reasonable basis for explaining the reported benefits of using this probiotic in vaginal candidiasis. Our data invite the consideration of this S. cerevisiae-based probiotic for initial clinical trials in humans.

\section{Conflict of interest}

This work was realised in the frame of a service agreement supported by Lesaffre International.

The authors declared no conflict of interest.

\section{References}

Badia, R., Brufau, M.T., Guerrero-Zamora, A.M., Lizardo, R., Dobrescu, I., Martin-Venegas, R., Ferrer, R., Salmon, H., Martinez, P. and Brufau, J., 2012. Beta-galactomannan and Saccharomyces cerevisiae var. boulardii modulate the immune response against Salmonella enterica serovar Typhimurium in porcine intestinal epithelial and dendritic cells. Clinical and Vaccine Immunology 19: 368-376.

Bistoni, F., Vecchiarelli, A., Cenci, E., Puccetti, P., Marconi, P. and Cassone, A., 1986. Evidence for macrophage-mediated protection against lethal Candida albicans infection. Infection and Immunity 51: 668-674.

Cascio, V., Gittings, D., Merloni, K., Hurton, M., Laprade, D. and Austriaco, N., 2013. S-Adenosyl-L-methionine protects the probiotic yeast, Saccharomyces boulardii, from acid-induced cell death. BMC Microbiology 13: 35.

Cassone, A., Vecchiarelli, A. and Hube, B., 2016. Aspartyl proteinases of eukaryotic microbial pathogens: from eating to heating. PLoS Pathogens 12: e1005992.

Cavaglieri, C.R., Nishiyama, A., Fernandes, L.C., Curi, R., Miles, E.A. and Calder, P.C., 2003. Differential effects of short-chain fatty acids on proliferation and production of pro- and anti-inflammatory cytokines by cultured lymphocytes. Life Science 73: 1683-1690.

Cayzeele-Decherf, A., Pelerin, F., Leuillet, S., Douillard, B., Housez, B., Cazaubiel, M., Jacobson, G.K., Justen, P. and Desreumaux, P., 2017. Saccharomyces cerevisiae CNCM I-3856 in irritable bowel syndrome: an individual subject meta-analysis. World Journal of Gastroenterology 23: 336-344.
Cheung, Q.C., Yuan, Z., Dyce, P.W., Wu, D., DeLange, K. and Li, J., 2009. Generation of epidermal growth factor-expressing Lactococcus lactis and its enhancement on intestinal development and growth of earlyweaned mice. American Journal of Clinical Nutrition 89: 871-879.

Dalmasso, G., Loubat, A., Dahan, S., Calle, G., Rampal, P. and Czerucka, D., 2006. Saccharomyces boulardii prevents TNF-alpha-induced apoptosis in EHEC-infected T84 cells. Research in Microbiology 157: 456-465.

Edwards-Ingram, L., Gitsham, P., Burton, N., Warhurst, G., Clarke, I., Hoyle, D., Oliver, S.G. and Stateva, L., 2007. Genotypic and physiological characterization of Saccharomyces boulardii, the probiotic strain of Saccharomyces cerevisiae. Applied and Environmental Microbiology 73: 2458-2467.

Finkel, J.S. and Mitchell, A.P., 2011. Genetic control of Candida albicans biofilm development. Nature Reviews Microbiology 9: 109-118.

Food and Agriculture Organization of the United Nations/World Health Organization (FAO/WHO), 2002. Guidelines for the evaluation of probiotics in food. Report of a Joint FAO/WHO working group on drafting guidelines for the evaluation of probiotics in food. Available at: http://tinyurl.com/zdbrkeg.

Gabrielli, E., Pericolini, E., Luciano, E., Sabbatini, S., Roselletti, E., Perito, S., Kasper, L., Hube, B. and Vecchiarelli, A., 2015. Induction of caspase-11 by aspartyl proteinases of Candida albicans and implication in promoting inflammatory response. Infection and Immunity 83: 1940-1948.

Gabrielli, E., Sabbatini, S., Roselletti, E., Kasper, L., Perito, S., Hube, B., Cassone, A., Vecchiarelli, A. and Pericolini, E., 2016. In vivo induction of neutrophil chemotaxis by secretory aspartyl proteinases of Candida albicans. Virulence 7: 819-825.

Hofs, S., Mogavero, S. and Hube, B., 2016. Interaction of Candida albicans with host cells: virulence factors, host defense, escape strategies, and the microbiota. Journal of Microbiology 54: 149-169.

Jubran, A., Grant, B.J., Duffner, L.A., Collins, E.G. Lanuza, D.M., Hoffman, L.A. and Tobin, M.J., 2013. Effect of pressure support vs unassisted breathing through a tracheostomy collar on weaning duration in patients requiring prolonged mechanical ventilation: a randomized trial. JAMA 309: 671-677.

Kennedy, P.J., Cryan, J.F., Dinan, T.G. and Clarke, G., 2014. Irritable bowel syndrome: a microbiome-gut-brain axis disorder? World Journal of Gastroenterology 20: 14105-14125.

Kurtzman, C.P. and Robnett, C.J., 1997. Identification of clinically important ascomycetous yeasts based on nucleotide divergence in the 5' end of the large-subunit (26S) ribosomal DNA gene. Journal of Clinical Microbiology 35: 1216-1223.

Kurtzman, C.P. and Robnett, C.J., 1998. Identification and phylogeny of ascomycetous yeasts from analysis of nuclear large subunit (26S) ribosomal DNA partial sequences. Antonie Van Leeuwenhoek 73: 331-371.

Lim, P.L., Toh, M. and Liu, S.Q., 2015. Saccharomyces cerevisiae EC1118 enhances the survivability of probiotic Lactobacillus rhamnosus HN001 in an acidic environment. Applied Microbiology and Biotechnology 99: 6803-6811.

Looijer-van Langen, M.A. and Dieleman, L.A., 2009. Prebiotics in chronic intestinal inflammation. Inflammatory Bowel Disease 15: 454-462. 
Martins, F.S., Silva, A.A., Vieira, A.T., Barbosa, F.H., Arantes, R.M., Teixeira, M.M. and Nicoli, J.R., 2009. Comparative study of Bifidobacterium animalis, Escherichia coli, Lactobacillus casei and Saccharomyces boulardii probiotic properties. Archives of Microbiology 191: 623-630.

Martins, F.S., Vieira, A.T., Elian, S.D., Arantes, R.M., Tiago, F.C., Sousa, L.P., Araujo, H.R., Pimenta, P.F., Bonjardim, C.A., Nicoli, J.R. and Teixeira, M.M., 2013. Inhibition of tissue inflammation and bacterial translocation as one of the protective mechanisms of Saccharomyces boulardii against Salmonella infection in mice. Microbes and Infection 15: 270-279.

Medzhitov, R., 2007. Recognition of microorganisms and activation of the immune response. Nature 449: 819-826.

Mennigen, R. and Bruewer, M., 2009. Effect of probiotics on intestinal barrier function. Annals of the New York Academy of Sciences 1165: 183-189.

European Office for Standardization (CEN), 2009. PCR typing of probiotic strains of Saccharomyces cerevisiae (yeast). Animal feeding stuffs, CEN/TS 15790.

Mosci, P., Gabrielli, E., Luciano, E., Perito, S., Cassone, A., Pericolini, E. and Vecchiarelli, A., 2014. Involvement of IL-17A in preventing the development of deep-seated candidiasis from oropharyngeal infection. Microbes and Infection 16: 678-689.

Moyes, D.L., Wilson, D., Richardson, J.P., Mogavero, S., Tang, S.X., Wernecke, J., Hofs, S., Gratacap, R.L., Robbins, J., Runglall, M., Murciano, C., Blagojevic, M., Thavaraj, S., Forster, T.M., Hebecker, B., Kasper, L., Vizcay, G., Iancu, S.I., Kichik, N., Hader, A., Kurzai, O., Luo, T., Kruger, T., Kniemeyer, O., Cota, E., Bader, O., Wheeler, R.T., Gutsmann, T., Hube, B. and Naglik, J.R., 2016. Candidalysin is a fungal peptide toxin critical for mucosal infection. Nature 532: 64-68.

Naglik, J.R., Fostira, F., Ruprai, J., Staab, J.F., Challacombe, S.J. and Sundstrom, P., 2006. Candida albicans HWP1 gene expression and host antibody responses in colonization and disease. Journal of Medical Microbiology 55: 1323-1327.

Naglik, J.R., Moyes, D., Makwana, J., Kanzaria, P., Tsichlaki, E., Weindl, G., Tappuni, A.R., Rodgers, C.A., Woodman, A.J., Challacombe, S.J., Schaller, M. and Hube, B., 2008. Quantitative expression of the Candida albicans secreted aspartyl proteinase gene family in human oral and vaginal candidiasis. Microbiology 154: 3266-3280.

Naglik, J.R., Moyes, D.L., Wachtler, B. and Hube, B., 2011. Candida albicans interactions with epithelial cells and mucosal immunity. Microbes and Infection 13: 963-976.

Naglik, J.R., Richardson, J.P. and Moyes, D.L., 2014. Candida albicans pathogenicity and epithelial immunity. PLoS Pathogens 10: e1004257.

Nicholson, J.K., Holmes, E., Kinross, J., Burcelin, R., Gibson, G., Jia, W. and Pettersson, S., 2012. Host-gut microbiota metabolic interactions. Science 336: 1262-1267.

Pericolini, E., Gabrielli, E., Amacker, M., Kasper, L., Roselletti, E., Luciano, E., Sabbatini, S., Kaeser, M., Moser, C., Hube, B., Vecchiarelli, A. and Cassone, A., 2015. Secretory aspartyl proteinases cause vaginitis and can mediate vaginitis caused by Candida albicans in mice. MBio 6: e00724.
Pericolini, E., Gabrielli, E., Ballet, N., Sabbatini, S., Roselletti, E., Cayzeele Decherf, A., Pelerin, F., Luciano, E., Perito, S., Justen, P. and Vecchiarelli, A., 2017. Therapeutic activity of a Saccharomyces cerevisiae-based probiotic and inactivated whole yeast on vaginal candidiasis. Virulence 8(1): 1-17.

Peters, B.M., Yano, J., Noverr, M.C. and Fidel Jr., P.L., 2014. Candida vaginitis: when opportunism knocks, the host responds. PLoS Pathogens 10: e1003965.

Pietrella, D., Pandey, N., Gabrielli, E., Pericolini, E., Perito, S., Kasper, L., Bistoni, F., Cassone, A., Hube, B. and Vecchiarelli, A., 2013. Secreted aspartic proteases of Candida albicans activate the NLRP3 inflammasome. European Journal of Immunology 43: 679-692.

Pietrella, D., Rachini, A., Pines, M., Pandey, N., Mosci, P., Bistoni, F., d'Enfert, C. and Vecchiarelli, A., 2011. Th17 cells and IL-17 in protective immunity to vaginal candidiasis. PLoS ONE 6: e22770.

Pineton de Chambrun, G., Neut, C., Chau, A., Cazaubiel, M., Pelerin, F., Justen, P. and Desreumaux, P., 2015. A randomized clinical trial of Saccharomyces cerevisiae versus placebo in the irritable bowel syndrome. Digestive and Liver Disease 47: 119-124.

Pontier-Bres, R., Munro, P., Boyer, L., Anty, R., Imbert, V., Terciolo, C., Andre, F., Rampal, P., Lemichez, E., Peyron, J.F. and Czerucka, D., 2014. Saccharomyces boulardii modifies Salmonella typhimurium traffic and host immune responses along the intestinal tract. PLoS ONE 9: e103069.

Ridge, J., Muller, J., Noguchi, P. and Chang, E.H., 1991. Dynamics of differentiation in human epidermoid squamous carcinoma cells (A431) with continuous, long-term gamma-IFN treatment. In vitro Cellular and Developmental Biology 27A: 417-424.

Sartor, R.B., 2005. Probiotic therapy of intestinal inflammation and infections. Current Opinion in Gastroenterology 21: 44-50.

Shimizu, S., 2004. Routes of administration. In: Hedrich, H.J. and Bullock, G. (eds.) The laboratory mouse. Elsevier, New York, NY, USA.

Sivignon, A., De Vallee, A., Barnich, N., Denizot, J., Darcha, C., Pignede, G., Vandekerckove, P. and Darfeuille-Michaud, A., 2015. Saccharomyces cerevisiae CNCM I-3856 prevents colitis induced by AIEC bacteria in the transgenic mouse model mimicking Crohn's disease. Inflammatory Bowel Disease 21: 276-286.

Sougioultzis, S., Simeonidis, S., Bhaskar, K.R., Chen, X., Anton, P.M., Keates, S., Pothoulakis, C. and Kelly, C.P., 2006. Saccharomyces boulardii produces a soluble anti-inflammatory factor that inhibits NF-kappaB-mediated IL-8 gene expression. Biochemical and Biophysical Research Communications 343: 69-76.

Spiller, R., Pelerin, F., Cayzeele Decherf, A., Maudet, C., Housez, B., Cazaubiel, M. and Justen, P., 2016. Randomized double blind placebo-controlled trial of Saccharomyces cerevisiae CNCM I-3856 in irritable bowel syndrome: improvement in abdominal pain and bloating in those with predominant constipation. United European Gastroenterology Journal 4: 353-362.

Sudbery, P.E., 2011. Growth of Candida albicans hyphae. Nature Reviews Microbiology 9: 737-748.

Tremaroli, V. and Backhed, F., 2012. Functional interactions between the gut microbiota and host metabolism. Nature 489: 242-249.

Van Niel, C.W., Feudtner, C., Garrison, M.M. and Christakis, D.A., 2002. Lactobacillus therapy for acute infectious diarrhea in children: a meta-analysis. Pediatrics 109: 678-684. 


\section{E. Gabrielli et al.}

Vance, R.E., Isberg, R.R. and Portnoy, D.A., 2009. Patterns of pathogenesis: discrimination of pathogenic and nonpathogenic microbes by the innate immune system. Cell Host Microbe 6: 10-21.

Vecchiarelli, A., Gabrielli, E. and Pericolini, E., 2015. Experimental models of vaginal candidiasis and inflammation. Future Microbiology 10: 1265-1268.
Wachtler, B., Wilson, D., Haedicke, K., Dalle, F. and Hube, B., 2011. From attachment to damage: defined genes of Candida albicans mediate adhesion, invasion and damage during interaction with oral epithelial cells. PLoS ONE 6: e17046.

Williams, N.T., 2010. Probiotics. American Journal of Health System Pharmacy 67: 449-458. 